Original Research Article

\title{
Use of anti-snake venom and clinical outcomes in snake envenomation: a prospective observational study
}

\author{
Shraddha M. Pore ${ }^{1}$, Arvind V. Kumbhar ${ }^{1}$, Ruchi D. Shah ${ }^{1}$, Praveenkumar T. Patil ${ }^{1 *}$, \\ Sachin M. Patankar ${ }^{2}$, Rohit N. Herekar ${ }^{2}$, Sunita J. Ramanand ${ }^{1}$
}

${ }^{1}$ Department of Pharmacology, ${ }^{2}$ Department of Medicine, Government Medical College, Miraj, Maharashtra, India

Received: 03 April 2017 Accepted: 28 April 2017

*Correspondence to: Dr. Praveenkumar T. Patil, Email: drpraveentpatil@ yahoo.in

Copyright: () the author(s), publisher and licensee Medip Academy. This is an openaccess article distributed under the terms of the Creative Commons Attribution NonCommercial License, which permits unrestricted noncommercial use, distribution, and reproduction in any medium, provided the original work is properly cited.

\begin{abstract}
Background: The only effective measure to prevent or reverse most of the manifestations of venomous snake-bite is timely administration of antisnake venom (ASV) with or without adjunctive treatment as necessary in each case. But recently several concerns have been raised with regard to use of polyvalent ASV. Hence the present study was conducted to assess use of ASV, early adverse reactions to ASV, adjunctive treatment and clinical outcomes in snakebite patients, which would help to identify areas of problem and provide basis for planning strategies to increase rational use of drugs.

Methods: It was a prospective observational study approved by Institutional Ethics Committee. All indoor patients with systemic manifestations of snake envenomation were included in the study. All participants gave written informed consent. Data was obtained prospectively using a structured case record form. Descriptive statistics was used to express the results.

Results: Among 52 patients, snake-bite predominantly affected males (59.62\%) than females $(40.38 \%)$. The most common site of snake-bite was lower limb $(65.38 \%)$. The main indication for ASV administration was vasculotoxic snakebite $(59.62 \%)$. Mean dose of ASV use was $18.21 \pm 15.51$ vials. Mortality was seen in one patient. Majority of patients $(28 / 52,53.85 \%)$ received ASV in the range of 1-10 vials for the management of snake-bite.

Conclusions: The use and dose of ASV was appropriate in vasculotoxic snakebite while few neurotoxic snake-bite patients needed higher than recommended dose.
\end{abstract}

Keywords: Adverse drug reactions, Anti snake venom, Prophylactic premedication, Snake bite, Systemic envenomation

\section{INTRODUCTION}

Snake-bite is an acute life- threatening, time limiting medical emergency and a major public health concern in India especially in rural areas. Direct estimates from a national mortality survey of 1.1 million homes by Mohapatra et al, show that there are about 45,900 annual snake-bite deaths nationally. ${ }^{1}$

The only effective measure to prevent or reverse most of the manifestations of venomous snake-bite is timely administration of antisnake venom (ASV) with or without adjunctive treatment as necessary in each case. ${ }^{2}$ In India, polyvalent ASV produced by hyperimmunising horses against venoms of four common species of snake i.e. "Big Four" believed to be responsible for most deaths is widely used as precise identification of snake species is generally not possible. But recently several concerns have been raised with regard to use of polyvalent ASV. Given wide geographical and intraspecies variation in antigenicity of snake venoms and identification of other medically important snakes besides "Big Four" presently available ASV cannot be assumed to be uniformly effective especially in regions away from source of immunizing venoms. ${ }^{3-10}$ Previous studies show that there is wide variation in management of snake-bite with respect to use of ASV, adjunctive treatment etc., although national snakebite management protocol and WHO guidelines for management of snakebite in South East 
Asia are in place for quite long time. ${ }^{11-17}$ Besides, limited availability and higher cost of ASV therapy are also well known.

With this background, we undertook the present study to assess use of ASV, early adverse reactions to ASV, adjunctive treatment and clinical outcomes in snakebite patients, since such data would help to identify areas of problem and provide basis for planning strategies to increase rational use of drugs.

\section{METHODS}

This prospective observational study was conducted at two tertiary care teaching hospitals affiliated to the same institute. The study was approved by institutional ethics committee. All participants gave written informed consent. All indoor patients irrespective of age and gender, showing systemic manifestations of snake envenomation were included in the study. Patients without systemic manifestations of snake envenomation, in whom adequate history could not be elicited due to problems such as language barrier and patients not willing to participate were excluded.

The protocol for management of patients with snakebites in these centers is as follows. All patients with suspected snakebite are admitted to ICU. They are monitored for at least 24 hours. ASV is administered to patients showing signs of systemic envenomation like clinically important coagulation abnormality or systemic effects such as ptosis or respiratory weakness. The initial and repeat doses are administered as clinically indicated. The ICU of these centers is equipped with ventilators and has facilities for haemodialysis.

The enrolled patients were observed from hospitalization to discharge or death. Information regarding demographics, type of snake-bite and its severity, details of ASV administration, pre medications, supportive treatment, occurrence of early adverse reactions to ASV and clinical outcomes etc. was obtained prospectively using a structured case record form.

\section{Statistical analysis}

Data was entered in Microsoft excel sheet. Descriptive statistics was used to express results about ASV use, early adverse reactions, premedication and clinical outcomes.

\section{RESULTS}

Data of 52 patients, satisfying inclusion and exclusion criteria, were available for analysis. Three patients received ASV without any apparent indication. These were excluded from analysis.

Mean age of the patient was $40.62 \pm 14.33$ years. Snakebite predominantly affected males $(59.62 \%)$ than females
(40.38\%). The most common site of snake-bite was lower limb $(65.38 \%)$. Mean length of hospital stay after snake bite was $4.73 \pm 3.41$ days (Table 1 ).

The main indication for ASV was vasculotoxic snake-bite in $59.62 \%$ of cases followed by neurotoxic snake-bite in $38.46 \%$ of cases. Mean dose of ASV use was $18.21 \pm 15.51$ vials. Mean time gap between snake-bite and first dose of ASV administration was 3.20 \pm 2.89 hours. Prophylactic medication, chlorpheniramine + hydrocortisone, was given in $26.92 \%$. About $15.38 \%$ of patients experienced early reaction to ASV. Mortality was seen in one patient. Adjunctive treatment in the form of fresh frozen plasma, ventilatory support, debridement, dressing and oxygen supply was needed in (19/52, $36.53 \%$ ) patients. $40.38 \%$ patients were given neostigmine + glycopyrrolate (Table 2).

From Figure 1, majority of patients (28/52, 53.85\%) received ASV in the range of 1-10 vials for the management of snake-bite.

In the present study, none of the vasculotoxic snake-bite patients required $>30$ vials, whereas $(5 / 20,25 \%)$ neurotoxic snake-bite patients required $>20 \mathrm{ASV}$ vials for management (Figure 2 and 3 ).

\section{DISCUSSION}

Snake-bite and deaths due to snake envenomation has been identified as serious medical problem in rural India since pre-independence era. ${ }^{3}$ In view of multiple issues raised with current ASV immunotherapy, region specific surveillance of ASV use and snake-bite management has assumed importance. ${ }^{18}$ This prospective observational study of one year duration was aimed at assessing use of ASV, early adverse reactions to ASV, adjunctive treatment and clinical outcomes in two tertiary care government teaching hospitals.

Table 1: Demographic and other baseline characteristics of patients of snake bite $(n=52)$.

\begin{tabular}{|lll|}
\hline Characteristics of patients & Value \\
\hline \multirow{2}{*}{ Age (years) } & Mean & $40.62( \pm 14.33)$ \\
\hline \multirow{2}{*}{ Gender } & Range & $17-70$ \\
\hline \multirow{2}{*}{ Site of snake bite } & Male & $31(59.62 \%)$ \\
\cline { 2 - 3 } & Female & $21(40.38 \%)$ \\
\cline { 2 - 3 } & Upper limb & $15(28.85 \%)$ \\
\cline { 2 - 3 } $\begin{array}{l}\text { Length of hospital limb } \\
\text { stay (days) }\end{array}$ & Trunk & $34(65.38 \%)$ \\
\hline
\end{tabular}

Demographic characteristics (Table 1) of study population shows, that snake-bite predominantly affects young males and lower limb was the most common site of bite. Vasculotoxic snake-bite was common than neurotoxic snake-bite and mean hospital stay was 
4.73 \pm 3.41 days. Our findings are supported by several previous studies. ${ }^{13,19,20}$ The mean time lag between bite and first dose of ASV was 3.20 2.89 hours, which was more or less similar to previous studies. ${ }^{13,21}$

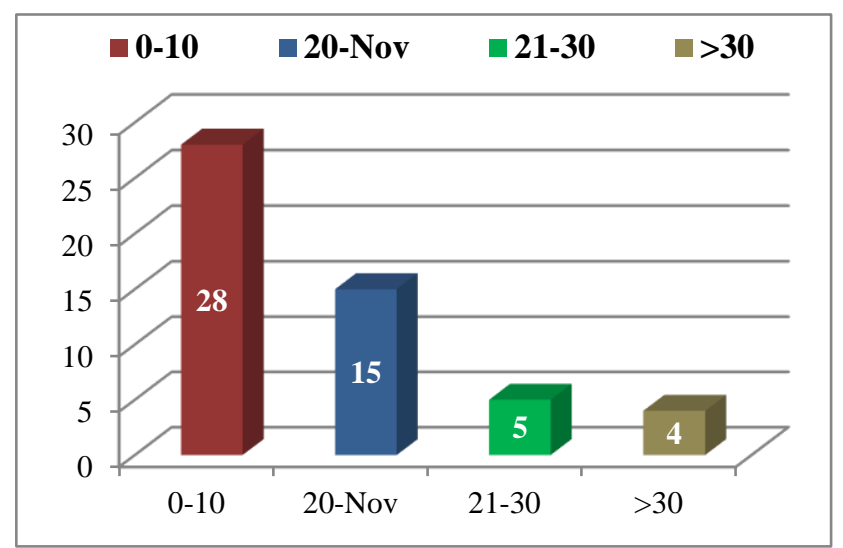

Figure 1: Frequency distribution of ASV vials used $(n=52)$.

Mean dose of ASV in the present study was $18.21 \pm 15.51$ Vials. The frequency distribution (Figure 1) shows that majority of patients required ASV in the range of 1-10 vials.

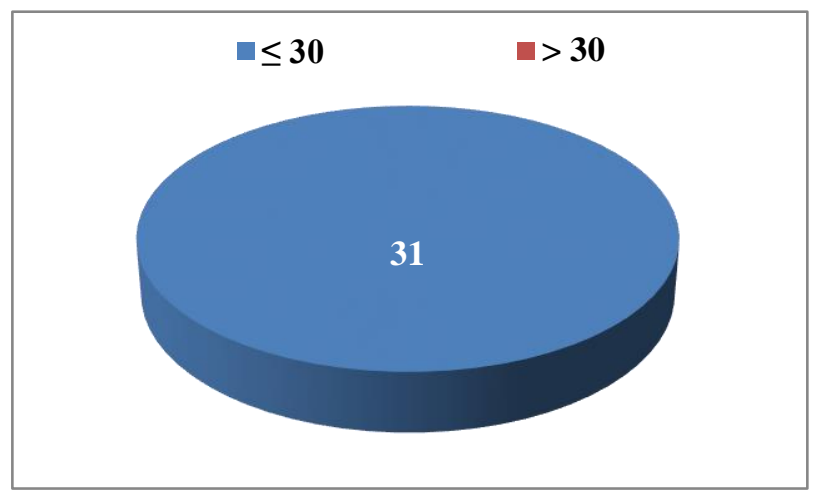

Figure 2: Number of vasculotoxic patients given recommended dose of $\mathrm{ASV}$ vials $(\mathrm{n}=31)$.

From Figure 2 and 3, all the vasculotoxic snake-bite patients (31) required $\leq 30$ vials of ASV, while majority of neurotoxic snake-bite patients $(15 / 20,75 \%)$ required $\leq 20$ vials. Based on the range of venom injected, the current Indian guidelines recommend maximum dose of 20 vials for neurotoxic and maximum dose of 30 vials for neurotoxic snake-bites. ${ }^{2}$ But in the present study none of vasculotoxic snake-bite patient required $>30 \mathrm{ASV}$ vials, while about $(5 / 20,25 \%)$ neurotoxic snake-bite patients required $>20 \mathrm{ASV}$ vials. This finding may indicate low potency of ASV in some patients. Previous retrospective study conducted in these hospitals also documented high ASV use in about one-fourth of patients. ${ }^{22} \mathrm{~A}$ hospital based prospective study by Saravu et al, showed an increase in dose of ASV with an increase in severity grade with corresponding delay in 'bite to needle time'. ${ }^{13}$
Some other studies have shown higher ASV dose for elapid bites or for viper bites. ${ }^{20,23,24}$ In a recent study by Kakaria et al, reports timely institution of ventilatory support and fixed dose of $200 \mathrm{ml}$ of ASV along with anticholinesterase treatment to be sufficient even in severe elapid bites. ${ }^{25}$

Table 2: Indication, dose of ASV, premedication and clinical outcomes $(n=52)$.

\begin{tabular}{|c|c|c|}
\hline Characteristics & & Value \\
\hline \multirow{3}{*}{ Indications of ASV } & Vasculotoxicity & $\begin{array}{l}31 \\
(59.62 \%)\end{array}$ \\
\hline & Neurotoxicity & $\begin{array}{l}20 \\
(38.46 \%)\end{array}$ \\
\hline & $\begin{array}{l}\text { Neurotoxicity+ } \\
\text { Vasculotoxicity }\end{array}$ & $1(1.92 \%)$ \\
\hline \multirow{2}{*}{$\begin{array}{l}\text { Dose of ASV } \\
\text { (vials) }\end{array}$} & Mean \pm SD & $\begin{array}{l}18.21 \\
( \pm 15.51)\end{array}$ \\
\hline & Range & $3-80$ \\
\hline \multirow{2}{*}{$\begin{array}{l}\text { Time gap* (hours) } \\
\text { between the snake } \\
\text { bite and first dose } \\
\text { of ASV } \\
\text { administration }\end{array}$} & Mean \pm SD & $3.2( \pm 2.89)$ \\
\hline & Range & $0.5-17$ \\
\hline \multirow{3}{*}{$\begin{array}{l}\text { Prophylactic } \\
\text { premedication }\end{array}$} & $\begin{array}{l}\text { Chlorpheniramine } \\
+ \text { Hydrocortisone }\end{array}$ & $\begin{array}{l}14 \\
(26.92 \%)\end{array}$ \\
\hline & $\begin{array}{l}\text { Only } \\
\text { hydrocortisone }\end{array}$ & $1(1.92 \%)$ \\
\hline & Not given & $\begin{array}{l}37 \\
(71.15 \%)\end{array}$ \\
\hline \multirow{5}{*}{ Reaction to ASV } & $\begin{array}{l}\text { Patients } \\
\text { experiencing early } \\
\text { reaction }\end{array}$ & $8(15.38 \%)$ \\
\hline & Urticaria & $3(5.77 \%)$ \\
\hline & Anaphylaxis & $2(3.85 \%)$ \\
\hline & Giddiness & $3(5.77 \%)$ \\
\hline & Allergic reaction & $2(3.85 \%)$ \\
\hline \multirow{3}{*}{ Clinical outcome } & Cured & $\begin{array}{l}35 \\
(67.34 \%)\end{array}$ \\
\hline & Cellulitis & $\begin{array}{l}16 \\
(30.77 \%)\end{array}$ \\
\hline & Death & $1(1.92 \%)$ \\
\hline \multirow{7}{*}{$\begin{array}{l}\text { Supportive } \\
\text { treatment }\end{array}$} & $\begin{array}{l}\text { Fresh frozen } \\
\text { plasma }\end{array}$ & $2(3.85 \%)$ \\
\hline & $\begin{array}{l}\text { Mechanical } \\
\text { ventilation }\end{array}$ & $4(7.69 \%)$ \\
\hline & Dressing & $\begin{array}{l}11 \\
(21.15 \%)\end{array}$ \\
\hline & $\begin{array}{l}\text { Fasciotomy and } \\
\text { debridement }\end{array}$ & $1(1.92 \%)$ \\
\hline & $\begin{array}{l}\text { Oxygen by high } \\
\text { flow mask }\end{array}$ & $1(1.92 \%)$ \\
\hline & Nil & $\begin{array}{l}33 \\
(63.46 \%)\end{array}$ \\
\hline & $\begin{array}{l}\text { Neostigmine+ } \\
\text { Glycopyrolate }\end{array}$ & $\begin{array}{l}21 \\
(40.38 \%)\end{array}$ \\
\hline
\end{tabular}




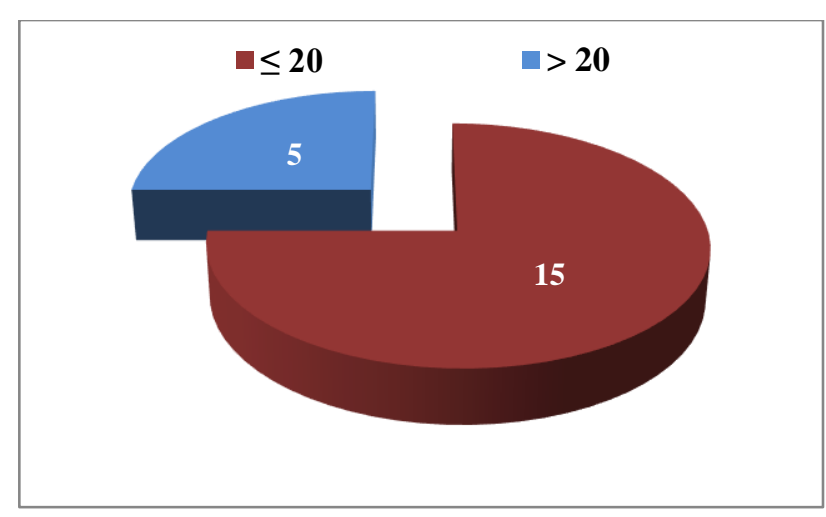

Figure 3: Number of neurotoxic patients given recommended dose of $\mathrm{ASV}$ vials $(n=20)$.

About $15.38 \%$ of patients in the present study experienced early reaction to ASV (Table 2). All of these reactions were symptomatically treated and ASV therapy was completed successfully in all patients. This suggests that early reactions to ASV is not an important concern in ASV therapy, although occasionally serious ADRs to ASV or very high incidence of anaphylaxis have been reported with ASV therapy. ${ }^{26,27}$

Sensitivity testing or prophylactic premedication to prevent early hypersensitivity reactions to ASV is not recommended by National or International guidelines. But prophylactic premedication with hydrocortisone \pm antihistaminic was used in $26.92 \%$ of patients in the present study. Mortality rate in the present study was $1.92 \%$. Previous studies have reported variable mortality rates and increased mortality has been associated with severity of envenomation neurotoxic snake-bites and delayed ASV therapy. ${ }^{13,19,20,22,28-31}$

\section{CONCLUSION}

Thus in the present study, ASV dose and use was appropriate in the vasculotoxic snake-bites, while $25 \%$ of the neurotoxic snake-bite patients required more than 20 vials. Prophylactic medication to prevent early ADRs to ASV was used in about one-fourth of patients. These findings point towards need for development of appropriate hospital based protocol and training of physicians involved in management of snake-bite. Availability of region specific, highly potent antivenoms would also be highly desirable.

Funding: No funding sources

Conflict of interest: None declared

Ethical approval: The study was approved by the Institutional Ethics Committee

\section{REFERENCES}

1. Mohapatra B, Warrell DA, Suraweera W, Bhatia P, Dhingra N, et al. Snakebite Mortality in India: A Nationally Representative Mortality Survey. PLoS Negl Trop Dis. 2011;5:1-8.
2. Ministry of Health and Family Welfare. Standard treatment guidelines: management of Snake Bite quick reference guide. 2016. Available from: https://www.medbox.org/management...snake-bitequick-reference-guide/download.

3. Whitaker R, Whitaker S. Venom, antivenom production and the medically important snakes of India. Curr Sc. 2012;103:635-43.

4. Venkatesh M, Prasad N, Sing T, Gowda V. Purifi cation, characterization, and chemical modifi cation of neurotoxic peptide from Daboia russelii snake venom of India. $\mathrm{J}$ Biochem Mol Toxicol. 2013;27:295-304.

5. Shashidharamurthy R, Kemparaju K. Region-specifi c neutralization of Indian cobra (Naja naja) venom by polyclonal antibody raised against the eastern regional venom: A comparative study of the venoms from three different geographical distributions. Int Immunopharmacol. 2007;7:61-9.

6. Pillai LV, Ambike D, Husainy S, Khaire A, Captain A, Kuch U. Severe neurotoxic envenoming and cardiac complications after the bite of a 'Sind Krait' (Bungarus cf. sindanus) in Maharashtra, India. Trop Med Health. 2012;40:103-8.

7. Kumar V, Sabitha P. Inadequacy of present polyspecific anti snakevenom: a study from central Kerala. Indian J Pediatr. 2011;78(10):1225-8.

8. Sharma LR, Lal V, Simpson ID. Snakes of medical significance in India: the first reported case of envenoming by the Levantine viper (Macrovipera lebetina). Wilderness Environ Med. 2008;19(3):1958 .

9. Kochar DK, Tanwar PD, Norris RL, Sabir M, Nayak $\mathrm{KC}$, Agrawal TD et al. Rediscovery of severe sawscaled viper (Echis sochureki) envenoming in the Thar desert region of Rajasthan, India. Wilderness Environ Med. 2007;18(2):75-85.

10. Ali SA, Yang DC, Jackson TN, Undheim EA, Koludarov I, Wood $\mathrm{K}$, et al. Venom proteomic characterization and relative antivenom neutralization of two medically important Pakistani elapid snakes (Bungarus sindanus and Naja naja). J Proteomics 2013;89:15-23.

11. Pandey DP, Vohra R, Stalcup P, Shrestha BR. A season of snakebite envenomation: presentation patterns, timing of care, anti-venom use, and case fatality rates from a hospital of south central Nepal. J Venom Res. 2016;7:1-9.

12. Singh J, Bhoi S, Gupta V, Goel A. Clinical profile of venomous snake bites in north Indian Military Hospital. J Emerg Trauma Shock. 2008;1:78-80.

13. Saravu K, Somavarapu V, Shastry AB, Kumar R. Clinical profile, species-specific severity grading, and outcome determinants of snake envenomation: An Indian tertiary care hospital-based prospective study. Indian J Crit Care Med. 2012;16(4):187-92.

14. Bawaskar HS, Bawaskar PH, Punde DP, Inamdar MK, Dongare RB, Bhoite RR. Profile of snakebite envenoming in rural Maharashtra, India. J Assoc Physicians India. 2008;56:88-95. 
15. Jindal G, Mahajan V, Parmar VR. Antisnake Venom in a Neonate with Snake bite. Indian pediatrics. 2010;47:349-50.

16. Singh S, Singh G. Snake bite: Indian Guidelines and Protocol. Medicine update of API. 2013:424-6.

17. Warrell DA. WHO Guidelines for the management of snake-bites. 2010:1-162.

18. Gupta YK, Peshin SS. Snake Bite in India: Current Scenario of an Old Problem. J Clin Toxicol. 2014;4:182.

19. Monteiro FN, Kanchan T, Bhagavath P, Kumar GP, Menezes RG, Yoganarasimha K. Clinicoepidemiological features of viper bite envenomation: a study from Manipal, South India. Singapore Med J. 2012;53:203-7.

20. Sharma N, Chauhan S, Faruqi S, Bhat P, Varma S. Snake envenomation in a north Indian hospital. Emerg Med J. 2005;22:118-20.

21. Ahmed SM, Nadeem A, Islam MS, Agarwal S, Singh L. Retrospective analysis of snake victims in Northern India admitted in a tertiary level institute. J Anaesthesiol Clin Pharmacol. 2012;28:45-50.

22. Pore SM, Ramanand SJ, Patil PT, Gore AD, Pawar MP, Gaidhankar SL, et al. A retrospective study of use of polyvalent anti-snake venom and risk factors for mortality from snake bite in a tertiary care setting. Indian J Pharmacol. 2015;47:270-4.

23. Sharma SK, Koirala S, Dahal G. Krait bite requiring high dose antivenom: a case report. Southeast Asian J Trop Med Public Health. 2002;33:170-1.

24. Jacob J. Viper bite with continuous defibrination despite adequate treatment with antivenom. J Assoc Physicians India. 2006;54:733-4.

25. Kakaria A, Narkhede M, Agrawal S, Bhavsar A, Nukte V. A study of outcome of neuroparalytic snake bite patients treated with fixed dose of antisnake venom. Int J Res Med Sci. 2014;2:1676-82.

26. Singh A, Biswal N, Nalini P, Sethuraman, Badhe A. Acute pulmonary edema as a complication of antisnake venom therapy. Indian J Pediatr. 2001;68:81-2.

27. Amin MR, Mamun SMH, Rashid R, Rahman M, Ghose A, Sharmin S et al. Anti-snake venom: use and adverse reaction in a snake bite study clinic in bangladesh. J. Venom. Anim. Toxins incl. Trop. Dis. 2008;14:660-72.

28. Kalantri S, Singh A, Joshi R, Malamba S, Christine $\mathrm{H}$, Joseph E et al. Clinical predictors of in-hospital mortality in patients with snake bite: a retrospective study from a rural hospital in central India. Tropical Medicine and International Health. 2006;2:22-30.

29. Halesha BR, Harshavardhan L, Lokesh AJ, Channaveerappa PK, Venkatesh KB. A study on the clinico-epidemiological profile and the outcome of snake bite victims in a tertiary care centre in southern India. Journal of Clinical and Diagnostic Research. 2013;1:122-6.

30. Chaudhari TS, Patil TB, Paithankar MM, Gulhane RV, Patil MB. Predictors of mortality in patients of poisonous snake bite: Experience from a tertiary care hospital in Central India. Int J Crit Illn Inj Sci. 2014;4:101-7.

31. Natarajan UM, Natarajan N. A study of snake bite patients with reference to time of delay in management. Sch. J. App. Med. Sci. 2016;4:85-8.

Cite this article as: Pore SM, Kumbhar AV, Shah RD, Patil PT, Patankar SM, Herekar RN, et al. Use of anti-snake venom and clinical outcomes in snake envenomation: a prospective observational study. Int J Basic Clin Pharmacol 2017;6:1472-6. 